\title{
A Generalized Heat-Transfer Model for Shielded-Fire Household Cookstoves
}

\author{
Nordica A. MacCarty ${ }^{a^{*}}$, Kenneth M. Bryden ${ }^{\mathrm{b}}$ \\ ${ }^{a}$ Oregon State University, School of Mechanical, Industrial and Manufacturing Engineering, \\ 204 Rogers Hall, Corvallis OR 97331 USA \\ *Corresponding author: Nordica.MacCarty@oregonstate.edu \\ ${ }^{\mathrm{b}}$ Iowa State University, Department of Mechanical Engineering, 1620 Howe Hall, Ames, IA \\ 50011-2274, USA
}

\begin{abstract}
This paper presents an experimentally validated steady-state heat transfer model of a shieldedfire, natural-draft biomass cookstove suitable for conceptual design of the small household cookstoves used in developing countries. The input variables for the model included 10 geometrical design variables, 2 material design variables, and 3 operating conditions, any of which can be considered as design constraints as user preferences dictate. This model was validated using data from three previously published studies and included 63 geometric and operating variations of 15 design variables. The model results for thermal efficiency are within \pm $5 \%$ for 59 of the 63 designs and have an L2 norm error of 3.0\%. Parametric variations of design variables within the model can assist in the conceptual phase of design. In addition, the temperature and velocity profiles, location and magnitude of losses, and heat transfer
\end{abstract}


contributions through various modes and regions of the pot provide sufficient detail to improve the understanding of a cookstove system and support detailed design.

Keywords: biomass, cookstove, heat transfer, efficiency, model, optimization, design

NOMENCLATURE

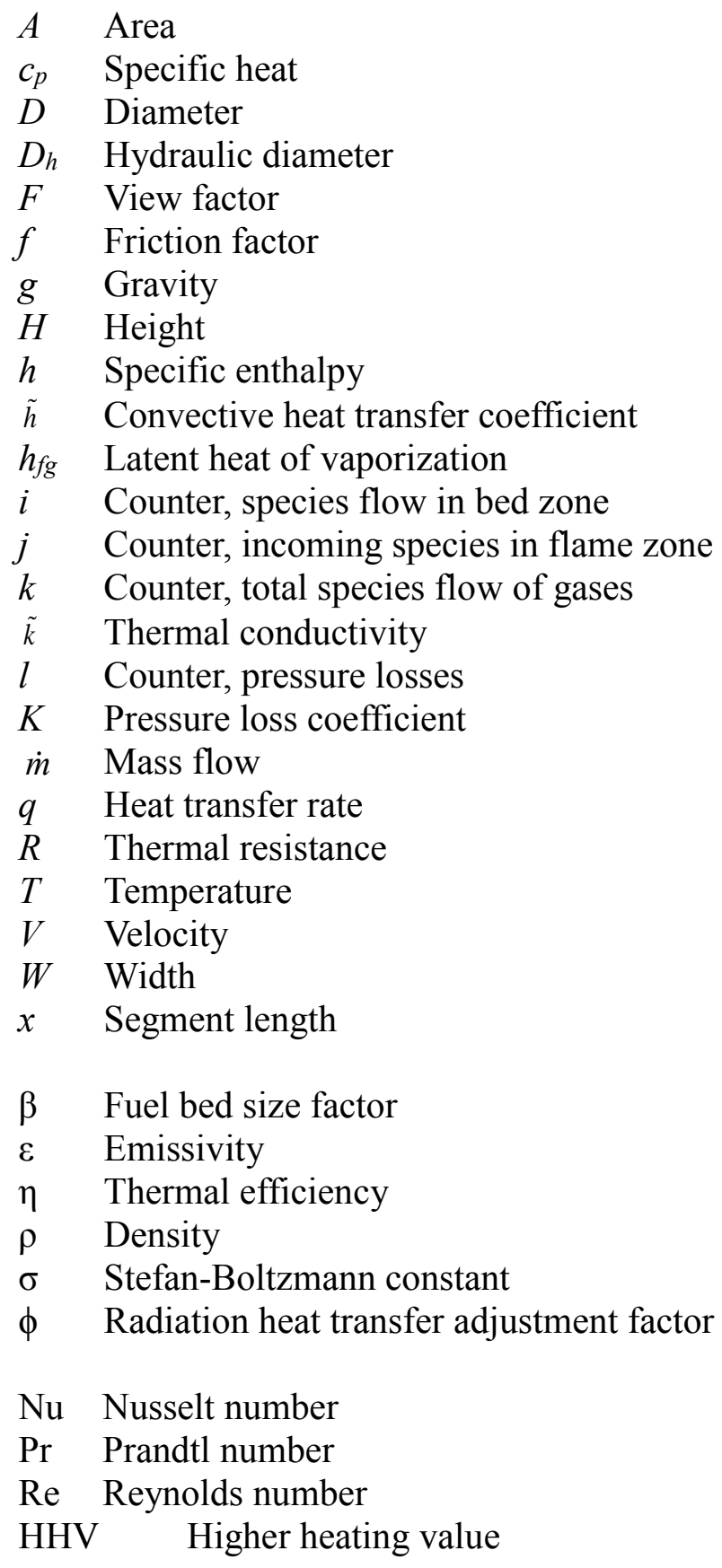

$\mathrm{Nu}$ Nusselt number

Pr Prandtl number

Re Reynolds number

HHV Higher heating value 


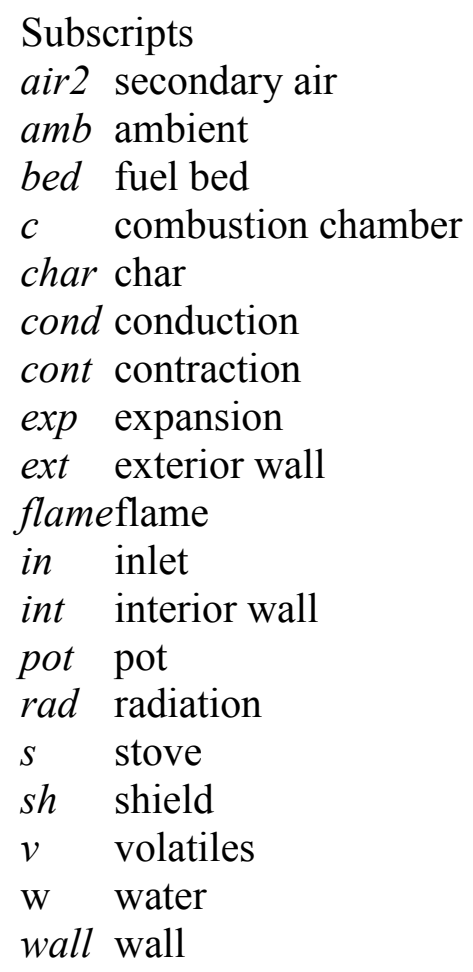

\section{Introduction and Background}

Approximately 2.7 billion people use solid biomass fuel in small stoves and three-stone fires to meet their household energy needs for cooking each day (IEA, 2010). This results in a number of adverse health, safety, community, and environmental effects including 4 million premature deaths each year, deforestation, and climate-changing emissions (Lim et al, 2012; Rehfuess, 2006; IEA, 2010; Bond and Sun, 2005). Recent projections indicate that use of biomass for cooking will increase and continue to be the dominant energy use in rural households through 2030 (IEA, 2010; Diaoglou, 2012). For example recent studies in the West African Sahel found that in rural villages $98 \%$ of household energy needs are met with small household cookstoves (Johnson and Bryden, 2012a; Johnson and Bryden, 2012b). For these subsistence-level families, the cost of acquiring biomass fuel to meet their household energy needs represents a significant 
fraction of time and income (Rehfuess, 2006). As a result the design, manufacture, and distribution of clean, low cost, high efficiency household cookstoves has been identified by many governmental and non-governmental organizations as a critical need to improve the lives of the resource-poor while concurrently addressing millennium development goals and slowing climate change.

To meet this need a number groups have over the past thirty years worked to research, develop, and design household cookstoves, with more than 160 stove projects currently operating worldwide (Ruiz-Mercado et al., 2011). In spite of this the design of cookstoves today is primarily a heuristic trial and error process based on previous experience, engineering judgment, rules of thumb, and experiment. Currently there is no dominant design basis or established design algorithm for optimizing the efficiency of these devices, nor are there validated and accepted models or modeling guidelines to support the design process. In addition, there is no standard methodology for stove testing and reporting such that experimental data can be used for model development and validation. Over the past 30 years fewer than 30 journal articles have been written on the computational modeling of household biomass cookstoves, with the majority of these activities focusing on a single stove design, and few of these provide detailed experimental validation of the computational results (MacCarty and Bryden, 2015a). This paper presents an experimentally validated model capable of predicting the heat transfer performance of small cookstoves over a wide range of combustion conditions and geometric variables. 


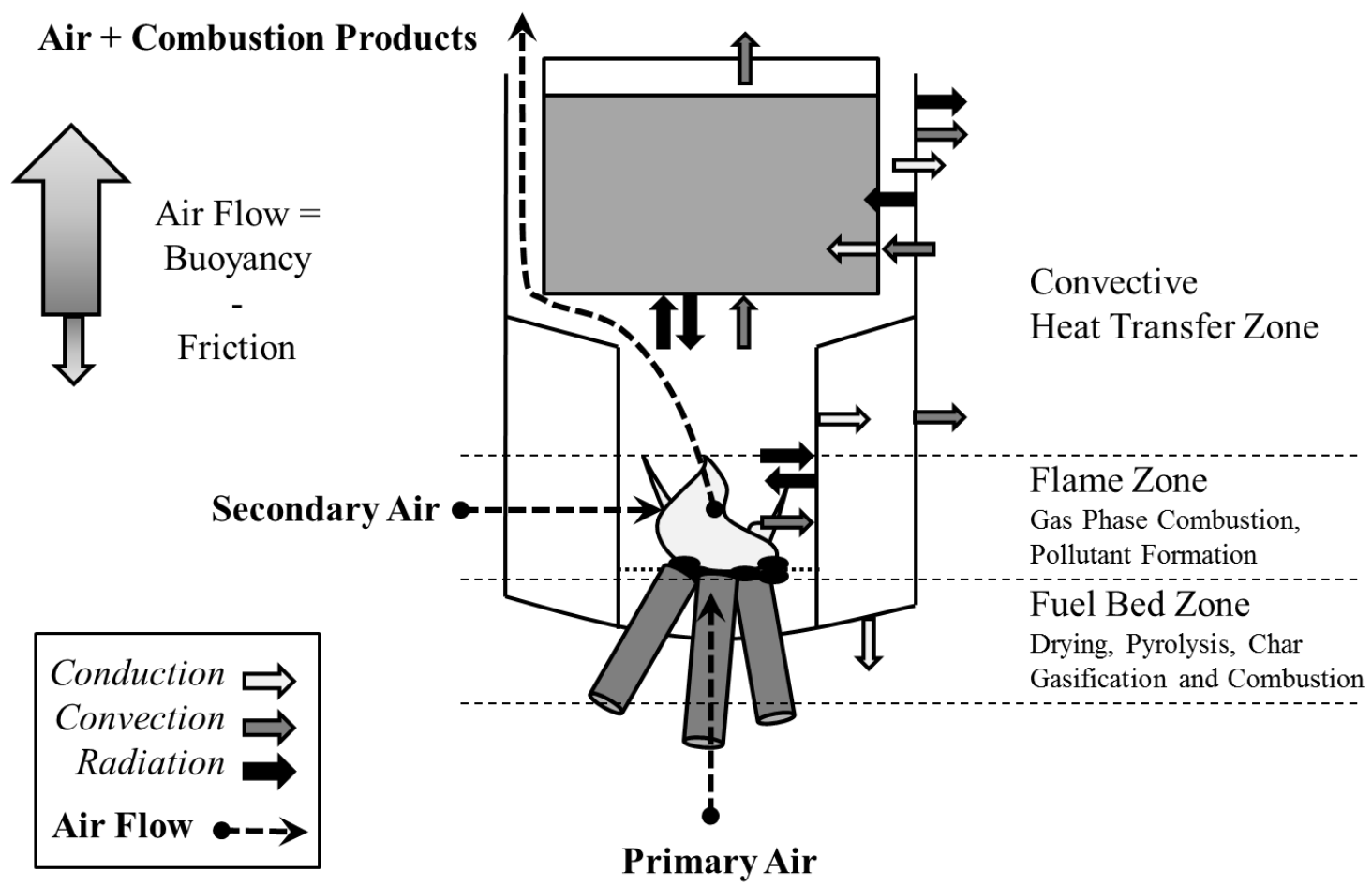

Figure 1. Combustion, flow, and heat transfer processes (adapted from MacCarty and Bryden, 2015a)

As shown in Figure 1, a typical natural draft biomass cooking stove is conceptualized as being composed of the air handling system, the combustion chamber, the convective heat transfer region, the cooking pot, and the support structure and insulation. For modeling purposes, this system can be divided into three zones: the solid phase packed bed zone, the gas phase combustion or flame zone, and the heat transfer zone. In the packed bed, solid phase combustion includes heating and drying of the wood followed by pyrolysis and char combustion with primary air. In the flame zone, secondary air enters, is heated, and is supplied to the gas phase combustion. In the heat transfer zone, energy is lost through the stove walls, transferred to the 
pot via convection and radiation, and exits as sensible losses. Fluid flow and the entrainment of excess air are driven by natural buoyancy, and is slowed by pressure losses due to friction throughout the various geometries of the flow path.

Three types of cookstove models have been developed by researchers: integral or zonal models, CFD models, and neural networks. Initial modeling efforts in the 1980s included algebraic and differential zonal models of open fires, shielded-fire stoves, and enclosed stoves, and focused on identifying equation sets for fluid flow and heat transfer throughout the system (De Lepeliere et al., 1981; Bussmann and Prasad, 1982; Bussmann, Visser, and Prasad, 1983; Bussmann and Prasad, 1986; Prasad, Sangen, and Visser, 1985). This was followed by investigation of specific regions such as wall losses or heat transfer correlations within a pot shield (Baldwin, 1987), or models of a specific stove design (Date, 1988; Kumar, Lokras, and Jagadish, 1990). After 2010, researchers continued to algebraically model specific stove designs (Agenbroad et al., 2011a and b, Zube, 2010) and some incorporated solid and gas phase combustion rates and efficiency (Shah and Date, 2011). Several researchers have used CFD packages for stove modeling (Burnham-Slipper 2007a and b, 2008; Gupta and Mittal, 2010a and b; Joshi et al, 2012; Ravi, Kohli, and Ray, 2002; Ravi, Sinha, and Jhalani, 2002) or for investigating heat transfer in specific regions of the stove (Wohlgemuth, Mazumder, and Andreatta, 2009; Urban, Bryden, and Ashlock, 2002; McCorkle, Bryden, and Carmichael, 2003; Bryden et al., 2003). Hannai et al. (2006) used a neural network based model to predict the thermal efficiency of cooking pots based on experimental data for varying pot radii, height, degree of curvature, material conductivity, and flame diameter. This model was then validated using separate experiments and used to determine the effects of different parameters on efficiency. As a result, the optimal cooking pot could be designed for a given situation, similar to 
the present goal with cookstoves. A more detailed discussion of past biomass cookstove modeling efforts is presented in the recent review by MacCarty and Bryden (2015a).

\section{Model Development}

As noted earlier, due to the lack of a suitable and accessible equation set, the current stove design process does not involve the assistance of computational modeling during the conceptual design phase, resulting in a missed opportunity for greater speed and accuracy in arriving at the most efficient design. To fill this gap, this paper presents a validated model for prediction of the steady-state thermal efficiency of a cylindrical, shielded-fire household cookstove with a natural draft air supply and flat-bottomed metal pot of diameter larger than the combustion chamber burning a continuous feed of wood sticks as fuel. Following a review of the literature, this general design was chosen as representative of the most common existing improved stove designs available today as shown by stove testing catalogs (Jetter et al., 2012; MacCarty, Still, and Ogle, 2010) and in-field studies. While cookstoves using prepared fuels or forced draft may offer good performance, these will require modifications to modeling techniques and data for validation and are therefore left for a later time. The present model is based on a review of past modeling efforts of heat transfer and fluid flow, and validated using 63 data points of experimental results from three previously published studies catalogued in (MacCarty and Bryden, 2015b). 


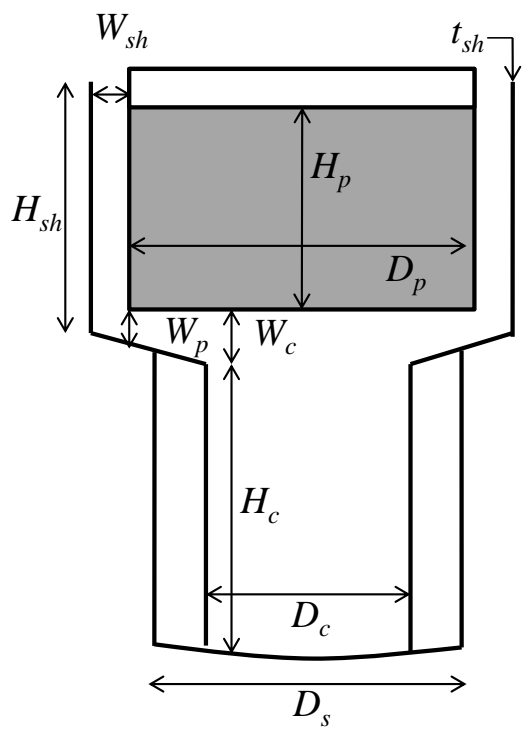

Figure 2. Stove geometry

The model utilizes 15 operational, geometrical, and material design variables as inputs.

The operating conditions include a constant given firepower, fuel heating value and as-received moisture content. The stove material and geometry are described by 12 design variables (Fig. 2):

- $\quad \mathrm{D}_{\mathrm{c}}-$ combustion chamber diameter

- $\mathrm{H}_{\mathrm{c}}-$ combustion chamber height

- $\mathrm{W}_{\mathrm{c}}$ - gap at the edge of the combustion chamber

- $\mathrm{W}_{\mathrm{p}}$ - gap at the edge of the pot bottom

- $\quad \mathrm{W}_{\mathrm{sh}}$ - gap between shield (if included) and pot

- $\mathrm{D}_{\mathrm{p}}-$ pot diameter

- $\mathrm{H}_{\mathrm{p}}$ - height of water in the pot based on water volume

- $\mathrm{D}_{\mathrm{s}}-$ stove combustion chamber body diameter 
- $\mathrm{k}_{\mathrm{s}}-$ stove body material conductivity (can account for multiple material layers via thermal resistance)

- $\mathrm{H}_{\mathrm{sh}}-$ height of shield, if included

- $\mathrm{t}_{\mathrm{sh}}$ - thickness of shield material

- $\mathrm{k}_{\mathrm{sh}}-$ shield material conductivity

Based on the experimental results available and current design and testing, the following assumptions are made:

- The operation is steady state.

- The firepower is given and sets the combustion rate.

- The fuel bed receives moist wood and underfire air as inputs. The wood is dried and pyrolyzed in the fuel bed producing water vapor, pyrolysis gases, and char. The char is combusted with oxygen to form carbon dioxide. The underfire air is stoichiometric with respect to the char combustion.

- The gases leaving the fuel bed leave at the temperature of the top surface of fuel bed.

- The fuel bed covers the entire bottom of the combustion chamber, which is assumed to be adiabatic.

- The pyrolysis gases are completely combusted with the overfire air.

- The thermodynamic properties of the combustion gases except for water vapor from fuel moisture are the same as air.

- Airflow within the combustion chamber is axisymmetric, one-dimensional, and vertical.

- The radial temperature is uniform in the theta direction. 
- Radiation heat transfer is idealized with radiant heat transfer only between surfaces with nonparticipating media. A radiation heat transfer adjustment factor, $\phi$, of 0.2 is introduced to account for view blockage and non-ideal radiative heat transfer.

- In the cases where the combustion chamber and stove top include multiple layers (such as metal surrounding insulation), conduction is determined through as total thermal resistance or taken as the material with the lowest thermal conductivity.

- The pot is a flat-bottomed, metal pot.

- Combustion constants and properties are shown in Table 1.

The model determines heat transfer and losses via the energy balance in the elements within each of the three zones within the stove.

Table 1. Properties and constants

\begin{tabular}{|c|c|c|}
\hline Property & Value & Reference \\
\hline \multirow[t]{6}{*}{$\begin{array}{l}\text { Wood } \\
\text { Combustion }\end{array}$} & $\begin{array}{l}\mathrm{CH}_{1.48} \mathrm{O}_{0.65}+1.05\left(\mathrm{O}_{2}+3.76 \mathrm{~N}_{2}\right) \rightarrow \mathrm{CO}_{2}+0.74 \mathrm{H}_{2} \mathrm{O}+3.93 \mathrm{~N}_{2} \\
\mathrm{f}_{(\mathrm{s})}=0.166\end{array}$ & $\begin{array}{l}\text { (Ragland and } \\
\text { Baker, 1991) }\end{array}$ \\
\hline & $\operatorname{AFR}_{(s)}=6.04$ (assumed for all experimental comparisons) & \\
\hline & $L H V=H H V-\left(\frac{m_{\mathrm{H}_{2} \mathrm{O}}}{m_{f}}\right) h_{f g}$ & \\
\hline & $\begin{array}{l}\text { Where } m_{\mathrm{H} 20} \text { is the sum of water as moisture in the fuel and } \\
\text { the water produced by the fuel hydrogen during } \\
\text { combustion }\end{array}$ & \\
\hline & $\begin{array}{l}\mathrm{HHV}_{\mathrm{f}, \mathrm{dry}}=20 \mathrm{MJ} / \mathrm{kg} \text { (assumed unless specifically provided } \\
\text { in (MacCarty and Bryden, 2015b) }\end{array}$ & \\
\hline & $L H V_{d r y}=y_{c h} H H V_{c h}+y_{v} L H V_{v}$ & \\
\hline $\begin{array}{l}\text { Char } \\
\text { Combustion }\end{array}$ & $\mathrm{y}_{\mathrm{ch}}=0.2$ & $\begin{array}{l}\text { (Bussmann } \\
\text { 1983, 1986, } \\
\text { 1988; Prasad }\end{array}$ \\
\hline
\end{tabular}




\begin{tabular}{|c|c|c|}
\hline & $\begin{array}{l}\mathrm{HHV}_{\mathrm{ch}}=32.8 \mathrm{MJ} / \mathrm{kg} \text { (assuming all carbon) } \\
\lambda_{\mathrm{ch}}=1 \\
\mathrm{C}+\left(\mathrm{O}_{2}+3.76 \mathrm{~N}_{2}\right) \rightarrow \mathrm{CO}_{2}+3.76 \mathrm{~N}_{2}\end{array}$ & $\begin{array}{l}\text { 1985; Ragland } \\
\text { 1991) }\end{array}$ \\
\hline Pot Details & $\begin{array}{l}\mathrm{T}_{\mathrm{p}}=373 \mathrm{~K} \\
\varepsilon_{\mathrm{p}}=1.0 \\
\mathrm{~F}_{\mathrm{b}-\mathrm{p}} \text { calculated per view factor of two parallel discs } \\
\mathrm{F}_{\text {stovetop-p }}=1.0 \\
\mathrm{~F}_{\text {sh-p }}=1.0\end{array}$ & \\
\hline Gas Properties & $\begin{array}{l}\text { Conductivity: } k=-2 \cdot 10^{-8} T^{2}+8 \cdot 10^{-5} T+0.0033 \mathrm{~W} / \mathrm{m} \cdot \mathrm{K} \\
\text { Density: } \rho=\frac{353.09}{T} \mathrm{~kg} / \mathrm{m}^{3} \\
\text { Enthalpy: } h=0.0725 T^{2}+984.49 T-7265.9 \mathrm{~J} / \mathrm{kg} \\
\text { Specific Heat: } c_{p}=0.145 T+984.49 \mathrm{~J} / \mathrm{kg} \cdot \mathrm{K} \\
\text { Viscosity: } \mu=-7 \cdot 10^{-12} T^{2}+4 \cdot 10^{-8} T+8 \cdot 10^{-6} \mathrm{~kg} / \mathrm{m} \cdot \mathrm{s} \\
\text { Specific heat of water vapor: } \\
c_{p, w}=-7 E-11 T^{3}+2 E-7 T^{2}+0.0005 T+1.6786 \mathrm{~kJ} / \mathrm{kg} \cdot \mathrm{K}\end{array}$ & (EES, 2011) \\
\hline Constants & $\begin{array}{l}\mathrm{g}=9.81 \mathrm{~m} / \mathrm{s}^{2} \\
\mathrm{~T}_{\mathrm{amb}}=298 \mathrm{~K} \\
\sigma=5.67 \mathrm{E}-8 \mathrm{~W} / \mathrm{m} 2 \cdot \mathrm{K}^{4} \\
\mathrm{~h}_{\mathrm{fg}}=2260 \mathrm{~kJ} / \mathrm{kg}\end{array}$ & \\
\hline
\end{tabular}

Within the packed bed, the feed rate of wood fuel is set by the assumed firepower. The underfire air is stoichiometric with respect to the char produced. The wood fuel is dried, 
pyrolyzed, and char combusted at a rate consistent with the feed rate of wood. The mass flow rate and enthalpy of wood, water vapor from fuel moisture, and gases (including air, pyrolysis, and carbon dioxide from char combustion) are tracked separately. The hot gases from the fuel bed enter the flame zone where they are mixed with the overfire air. The gas species except for the water vapor are assumed to have the same thermodynamic properties of air. An energy balance (Eq. 4) in the bed zone is used to solve for the temperature of the gases leaving the bed (Bussmann, Visser, and Prasad, 1983; Bussmann and Prasad, 1986).

$$
\begin{gathered}
\dot{m}_{\mathrm{char}} \mathrm{HHV}_{\mathrm{char}}=\sum_{i} \dot{m}_{i}\left(h_{\text {bed }, i}-h_{\text {amb }, i}\right)+\dot{m}_{w} h_{f g}+\phi_{\text {flame }} \varepsilon_{\mathrm{char}} \sigma A_{b e d} F_{\text {bed-pot }}\left(T_{\text {bed }}^{4}-T_{\text {pot }}^{4}\right)+ \\
\phi_{g} \varepsilon_{\text {char }} \sigma A_{\text {bed }}\left(1-F_{\text {bed-pot }}\right)\left(T_{\text {bed }}^{4}-T_{\text {wall }}^{4}\right)
\end{gathered}
$$

In the flame zone, an energy balance (Eq. 5) is used to determine the gas temperature at the inlet of the combustion chamber. It assumes instantaneous and complete combustion of the volatiles and no radiation loss from the flame.

$$
\dot{m}_{\mathrm{v}} \mathrm{HHV}_{\mathrm{v}}+\left[\sum_{j}\left[\dot{m}_{j} h_{j}\right]_{\text {bed }}+\left[\dot{m}_{\text {air } 2} h_{\text {air } 2}\right]_{\text {amb }}\right]_{\text {in }}=\sum_{j}\left[\dot{m}_{j} h_{j}\right]_{o u t}
$$

Hot gases from the flame zone enter the heat transfer zone, which is divided into five regions (Fig. 3). The combustion gases flow up through the combustion chamber (1), to the cooking pot center directly above the fuel bed and flame zone (2), to the cooking pot bottom beyond the edges of the combustion chamber (3), to the pot corner (4) and sides (5). Energy losses through the stove body and heat transfer to the pot are found by discretizing the energy conservation equation for each region. Regions 1, 3, and 5 are discretized into cylindrical or annular control volumes with user-defined thickness, $\Delta \mathrm{x}$, while regions 2 and 4 are each a single 
volume. Radiation heat transfer is modeled assuming blackbody radiation between surfaces with non-participating media and a radiation heat transfer adjustment factor fitted from experimental data. Convective heat transfer coefficients in various regions are taken from the existing heat transfer relationships or fitted to published experimental results.

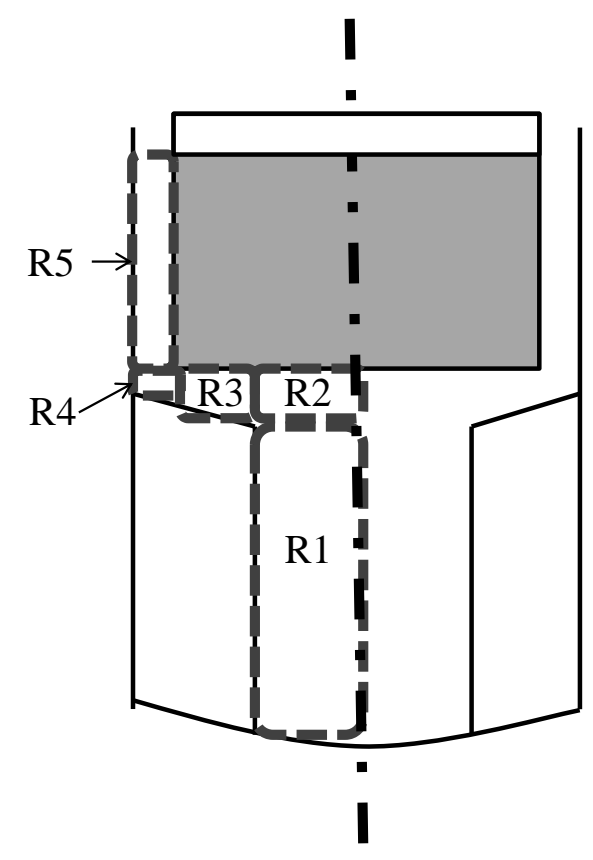

Figure 3. Regions of the stove

\section{Region 1: Combustion Chamber}

The combustion chamber is represented by control volumes as a series of stacked discs with vertical flow surrounded by the combustion chamber wall. Conservation of energy is used to determine the exit temperature of each volume (Eq. 6), with the initial inlet temperature equal to the flame temperature. The energy balance includes radiation from the fuelbed to the wall, and radiation from the wall to the pot, with the wall-to-wall radiation assumed net zero.

$\sum_{k} \dot{m}_{k}\left(h_{\text {flame }, k}-h_{\text {out }, k}\right)=\phi_{g} \sigma A_{p o t, \text { rad }} F_{\text {pot-wall }}\left(T_{\text {int }}^{4}-T_{p o t}^{4}\right)+\phi_{\text {flame }} \varepsilon_{\text {char }} \sigma A_{\text {bed }} F_{\text {bed-wall }}\left(T_{\text {int }}^{4}-T_{\text {bed }}^{4}\right)+q_{\text {wall }}$ 
Heat loss through the wall is represented by the analog model of thermal resistance (Eq. 7). Here radiative transport is treated as an equivalent convective term. In the cases of stoves with metal combustion chamber and exterior walls filled with insulation, only the insulative layer is considered. Multiple layers of material can be considered using the sum of the conductive resistances of each layer.

$$
q_{\text {wall }}=\frac{T_{i n}-T_{a m b}}{R_{\text {int }}+R_{\text {cond }}+R_{e x t}}=\frac{T_{i n}-T_{i n t}}{R_{i n t}}=\frac{T_{e x t}-T_{a m b}}{R_{e x t}}
$$

where

$$
\begin{gathered}
R_{\text {int }}=\frac{1}{\pi D_{c} H_{c}\left(\tilde{h}_{\text {int }}+\sigma \varepsilon_{\text {char }} A_{\text {bed }} F_{\text {bed-wall }}\left[\frac{\beta T_{b e d}^{4}+T_{p o t}^{4}-2 T_{\text {int }}^{4}}{T_{\text {in }}-T_{\text {int }}}\right]\right)} \\
R_{\text {ext }}=\frac{1}{\pi D_{s} H_{c}\left(1.42\left(\frac{T_{e x t}-T_{a m b}}{H_{s}}\right)^{0.25}+\sigma \varepsilon_{\text {wall }}\left[\frac{T_{e x t}^{4}-T_{a m b}^{4}}{T_{\text {ext }}-T_{a m b}}\right]\right)} \\
R_{c o n d}=\frac{\ln \left(D_{s} / D_{c}\right)}{2 \pi H_{c} \tilde{k}_{s}}
\end{gathered}
$$

Here a constant interior convective heat transfer coefficient of $10 \mathrm{~W} / \mathrm{m}^{2} \cdot \mathrm{K}$ is used for the interior convective heat transfer coefficient (Baldwin, 1987). Alternatively this can be calculated using the empirical correlation for free laminar convection along a vertical heated plate in air, $\tilde{h}=1.42(\Delta T / L)^{1 / 4}(\mathrm{Nag}, 2006)$, as in the denominator of Eq. (9). Using the vertical heated plate correlation, the value for the interior convective heat transfer coefficient varies between 5.8-13.4 $\mathrm{W} / \mathrm{m}^{2} \cdot \mathrm{K}$ with average $8.6 \mathrm{~W} / \mathrm{m} 2 \cdot \mathrm{K}$ and $\mathrm{L} 2$ error of $2.1 \mathrm{~W} / \mathrm{m}^{2} \cdot \mathrm{K}$ from $10 \mathrm{~W} / \mathrm{m} 2 \cdot \mathrm{K}$, representing 
an average change in predicted efficiency of $0.03 \%$ with maximum $0.3 \%$. Therefore the constant value is used. Heat flow is initially calculated using the interior and exterior wall temperatures from the previous iteration, which are then updated and bisection is used to determine the exit temperature of the gas.

\section{Region 2: Pot Bottom Center}

The single cylindrical region directly above the combustion chamber exit is treated as a stagnation point of average heat transfer to the pot only with no losses (Eq. 11).

$$
\sum_{k} \dot{m}_{k}\left(h_{i n, k}-h_{\text {out }, k}\right)=\tilde{h} \pi\left(\frac{D_{c}}{2}\right)^{2}\left(T_{i n}-T_{p o t}\right)
$$

The potential convective heat transfer correlations are presented in Table 2, including correlations from the literature (Eqs. 12-14) or optimization of the form of Eq. (15). These correlations were investigated to determine which correlation gave best prediction of the experimental data set. Analysis concluded that the correlation from (Bussmann, Visser, and Prasad, 1983) (Eq. 14) with $\mathrm{D}_{\text {plume }}=\mathrm{D}_{\mathrm{c}}$ gave the best agreement of published options.

Table 2. Options for $\mathrm{Nu}$ at the pot bottom center

Method Equation

\begin{tabular}{ll}
\hline $\begin{array}{l}\text { Entire pot bottom (Bussmann } \\
\text { and Prasad, 1986) }\end{array}$ & $\mathrm{Nu}_{D_{\text {plume }}}=1.26 \operatorname{Pr}^{0.42} \operatorname{Re}_{D_{\text {plume }}}\left(\frac{D_{p}}{D_{\text {plume }}}\right)^{-0.5}$ \\
Entire pot bottom (Shah and & $\mathrm{Nu}=0.5\left(1.65 \operatorname{Re}_{D_{c}}^{0.5}+2.733 \operatorname{Re}_{D_{c}}^{0.59}\right)$
\end{tabular}

Date, 2011) 
$\begin{aligned} & \text { Stagnation region in open fire } \\ & \text { (Bussmann, Visser, and Prasad, }\end{aligned} \quad \mathrm{Nu}_{D_{\text {plume }}}=1.03 \operatorname{Pr}^{0.42} \operatorname{Re}_{D_{\text {plume }}}^{0.5}\left(\frac{D_{c}}{D_{\text {plume }}}\right)^{-0.65}$ 1983)

Optimization Form

$$
\mathrm{Nu}=c_{1} \operatorname{Re}_{D_{c}}^{n_{11}}\left(\frac{D_{p}}{D_{c}}\right)^{n_{21}}
$$

Region 3: Pot Bottom above Stove body

This region consists of a series of coaxial annular rings of width $\Delta \mathrm{x}$ with a potentially sloped bottom which transfer heat to both the pot bottom through convection and radiation and stove body through convection and conduction (Eq. 16).

$$
\sum_{k} \dot{m}_{k}\left(h_{i n, k}-h_{\text {out }, k}\right)=\tilde{h} A_{p o t}\left(T_{i n}-T_{p o t}\right)+q_{\text {wall }}+\phi_{g} \sigma A_{p o t}\left(T_{i n t}^{4}-T_{p o t}^{4}\right)
$$

The view factor from the stovetop to pot bottom is assumed 1 (for infinite parallel plates), thus the area of the flat pot bottom is used for radiation calculations instead of the slightly sloped area of the stovetop and radiative heat transfer is neglected from the wall loss.

The convective heat transfer at the pot bottom is determined from the same two equation options as the center region (Eqs. 12 and 13) or a correlation from Bussmann's open fire work (Bussmann, Visser, and Prasad, 1983) beyond the stagnation region (Eq. 17).

$$
\mathrm{Nu}_{D_{\text {plume }}}=0.32 \operatorname{Pr}^{0.33} \operatorname{Re}_{D_{\text {plume }}}^{0.7}\left(\frac{r}{D_{\text {plume }}}\right)^{-1.23}
$$

Or it is optimized with the form with either the same or different values of $c_{1}, \mathrm{n}_{1}$, and $\mathrm{n}_{2}$ relative to region 2 (Eq. 18). 


$$
\mathrm{Nu}=c_{2} \operatorname{Re}_{D_{c}}^{n_{12}}\left(\frac{D_{p}}{D_{c}}\right)^{n_{22}}
$$

The convective heat transfer coefficient to the stovetop is assumed equal to that of the pot. Heat loss to the stovetop uses the same thermal resistance methods as region 1, with no radiation analog at the interior and conduction through the stove body ends at the cylindrical temperature profile determined at the exit of the combustion chamber (Eq. 19) where $r=r_{c}+i \Delta x$. If the stovetop is sloped, the wall thickness begins at zero and increases to the outside of the stove (Eq. 20). In the case of a stove with a body diameter smaller than that of the pot, thermal resistance through the stove wall thickness to ambient is used instead, including convection and radiation terms on each end.

$$
\begin{gathered}
T_{b o d y, i}=T_{e x t, H_{c}}-\left(T_{e x t, H_{c}}-T_{i n t, H_{c}}\right) \frac{\ln \left(r_{s} / r\right)}{\ln \left(r_{s} / r_{c}\right)} \\
t_{\text {wall }, i}=i \Delta x \frac{W_{c}-W_{p}}{r_{p}-r_{c}}
\end{gathered}
$$

\section{Region 4: Pot Corner}

In the single region at the pot corner, there is no heat transfer into the pot but there are losses to the stove body and shield (Eq. 21). Heat flux through the body is assumed to be equal to the wall flux in the final element of region 3. Heat flux through the shield in this region, if present, is assumed equal to the flux through the first element in region 5 from the previous iteration.

$$
\sum_{k} \dot{m}_{k}\left(h_{i n, k}-h_{\text {out }, k}\right)=q_{\text {wall,stovetop }}+q_{\text {wall }, \text { shield }}
$$

Region 5: Pot Sides 
At the pot sides the control volumes are a series of stacked annular rings of height $\Delta x$.

The calculation of heat transfer ends at the height of the water. If the shield is higher than this level, this additional height is considered in the buoyancy calculations only. The sides of the pot have three possible conditions: 1) completely unshielded 2) within a shield and 3) in an unshielded region past the height of an existing shield. Possible convective heat transfer correlations are shown in Table 3, and the energy balance is shown by Eq. (22).

$$
\sum_{k} \dot{m}_{k}\left(h_{i n, k}-h_{\text {out }, k}\right)=\tilde{h} A_{p o t}\left(T_{i n}-T_{p o t}\right)+q_{\text {wall }}+\phi_{g} \sigma A_{p o t}\left(T_{i n t}^{4}-T_{p o t}^{4}\right)
$$

Table 3. Convective heat transfer correlations at the pot sides

\begin{tabular}{llll}
\hline Method Equation & Eq. & Reference
\end{tabular}

\section{Unshielded Pot}

2-D turbulent

wall jet

$$
\mathrm{Nu}=0.25 \operatorname{Pr} \operatorname{Re}^{0.75}\left(\frac{z+12}{W_{\text {jet }, 0}}\right)^{-0.6}
$$

(Bussmann, Visser, and Prasad, 1983)

Forced convection laminar heated

$$
\mathrm{Nu}=0.664 \sqrt{\mathrm{Re}}
$$

plate

Vertical heated plate as loss

$$
\tilde{h}=-1.42\left(\frac{T_{p}-T_{a m b}}{H_{p}}\right)^{0.25}
$$

Turbulent flow

over isothermal $\quad \mathrm{Nu}_{x}=0.0296 \mathrm{Re}_{x}^{4 / 5} \operatorname{Pr}^{1 / 3}$ plate
(Prasad, Sangen and Visser, 1985)
(Shah and Date, 2011) 2007)
(Incropera et al.,

\section{Shielded Region}

$\begin{aligned} & \text { Thermally } \\ & \text { developing flow }\end{aligned} \overline{\mathrm{Nu}}=1.85\left(\operatorname{Re} \operatorname{Pr} \frac{2 W_{s h}}{H_{s h}}\right)^{1 / 3}$ in parallel plates
(Bussmann and

Prasad, 1986) 
Constant

Nusselt

$$
\overline{\mathrm{Nu}}=\frac{\tilde{h} \cdot W_{s h}}{k_{g}}=\mathrm{constant}=4.861
$$

(Baldwin, 1987)

Optimized

Format

$$
\overline{\mathrm{Nu}}=c_{3} \operatorname{Re}^{n_{13}}\left(\frac{2 W_{s h}}{D_{p}}\right)^{n_{23}}
$$

\section{Unshielded Region}

Flat plate in turbulent flow

$$
\mathrm{Nu}_{x}=0.0296 \operatorname{Re}_{L}^{4 / 5} \operatorname{Pr}^{1 / 3}
$$

(Incropera et al., 2007)

Radiation from shield to pot is considered for the shielded regions with a view factor of 1 using the average interior shield temperature from the previous iteration. Heat flux through the shield wall is calculated using thermal resistance, assuming an equal interior convective heat transfer coefficient as that of to the pot and calculated per the heated plate equation on the exterior. The interior and exterior include a separate radiation term (Eqs. 31 and 32) such that they are combined with the convective resistance at the interior or exterior (Eq. 33) in parallel (Eq. 34) (Baldwin, 1987), which is then combined in series with conduction through the shield in a method similar to that of the combustion chamber walls (Eq. 7).

$$
\begin{gathered}
R_{\text {rad,int }}=\frac{1}{A_{\text {sh,int }} \tilde{h}_{r a d, i n t}}=\frac{1}{A_{s h, i n t} \sigma \varepsilon\left(T_{s h, i n t}+T_{p}\right)\left(T_{s h, i n t}^{2}+T_{p}^{2}\right)} \\
R_{r a d, e x t}=\frac{1}{A_{s h, e x t} \tilde{h}_{r a d, e x t}}=\frac{1}{A_{s h, e x t} \sigma \varepsilon\left(T_{s h, e x t}+T_{a m b}\right)\left(T_{s h, e x t}^{2}+T_{a m b}^{2}\right)} \\
R_{c o n v}=\frac{1}{\tilde{h} A_{s h}}
\end{gathered}
$$




$$
R_{r a d+c o n v}=\frac{R_{r a d} R_{c o n v}}{R_{r a d}+R_{c o n v}}
$$

\section{Fluid Flow}

Fluid flow through the combustion chamber is determined by a momentum balance of airflow due to buoyancy and pressure losses through friction, bends, expansions, and contractions in the flow path (Eq. 35) which is used to determine exit velocity and thus total mass flow of gas.

$$
\frac{\rho_{\text {exit }} V_{e x i t}^{2}}{2}=g\left(H_{c}+W_{c}+H_{s h}\right)\left(\rho_{a m b}-\rho_{e x i t}\right)-\sum_{l} \rho_{l} \frac{V_{l}^{2}}{2}\left(\frac{f_{l} x_{l}}{D_{h, l}}+K_{l}\right)
$$

The exit of the stove for buoyancy calculations is considered to be the point where the flow exits the shield surrounding the pot, or from under the pot in an unshielded stove. The flow path is treated similar to pipe flow and includes pressure drop through 1) the fuel bed, 2) $90^{\circ}$ turn under the pot center, 3) gradual contraction or expansion from the combustion chamber along under the pot (the end of region 1 to end of region 3), 4) $90^{\circ}$ turn at the pot corner, 5) contraction or expansion to the pot side, and 6) the friction throughout the channels per volume height. Equations for these are shown in Table 4. A number of possible correlations for $\mathrm{K}_{\mathrm{cont}}$ along the bottom and side of the pot were available and are shown in Figure 4. The variable pressure drop coefficient in the bed, $K_{\text {bed }}$ was assumed zero for all stoves, as stoves of this type have generally been designed to have little air entry resistance with possibly limited flow through the grate but free flow of air above and around the fuel. An additional term of $\mathrm{K}_{\mathrm{bed}}=0.75$ was incorporated into the Envirofit stove from (Jetter et al., 2012) to reflect the effect of the reducer ring within the combustion chamber. 
Table 4. Fluid flow constants and equations

\begin{tabular}{llll}
\hline Property & Equation or Value & Eq. & Reference \\
\hline $\begin{array}{l}\text { Friction factor in } \\
\text { channels }\end{array}$ & Laminar $f_{l}=\frac{64}{\mathrm{Re}}$ & (36) & $\begin{array}{l}\text { (DeLepeliere, 1981) } \\
\text { Moody Diagram }\end{array}$ \\
& Turbulent $\mathrm{f}_{\mathrm{l}}=0.02-0.09$ & & (Shah and Date, 2011) \\
\hline $\begin{array}{l}90^{\circ} \text { turn at pot } \\
\text { corner }\end{array}$ & $K_{\text {bend }}=1.0$ & & (Shah and Date, 2011) \\
\hline $\begin{array}{l}\text { Gradual } \\
\text { contraction }\end{array}$ & ${ }^{\mathrm{a}} K_{\text {cont }}=0.5 \sin \phi\left(1-\frac{A_{l+1}}{A_{l}}\right)$ & (37) & (Shaughnessy, Katz, \\
& ${ }^{\mathrm{b}} K_{\text {cont }}=0.2053\left(\frac{A_{l}}{A_{l+1}}\right)^{2}-0.152 \frac{A_{l}}{A_{l+1}}$ & (38) & \\
& ${ }^{\mathrm{c}} K_{\text {cont }}=0.0504\left(\frac{A_{l}}{A_{l+1}}\right)^{2}-0.0033 \frac{A_{l}}{A_{l+1}}$ & (39) & (Shaughnessy, Katz, \\
& ${ }^{\mathrm{d}} K_{\text {cont }}=2.0\left(\frac{A_{l}}{A_{l+1}}\right)^{1 / 4}-2.0$ & & and Schaffer, 2005)
\end{tabular}

$\begin{array}{ll}\text { Gradual } \\ \text { expansion }\end{array} \quad K_{\exp }=\left(1-\frac{A_{l}}{A_{l+1}}\right)^{2} \quad$ (41) $\quad$ (Shah and Date, 2011)

${ }^{\mathrm{a}} \phi=$ half-angle of the contraction

${ }^{\mathrm{b}}$ curve fit from tabulated values for $90^{\circ}$ contraction at the pot side ${ }^{\circ}$ curve fit from tabulated values for $10^{\circ}$ contraction at the pot bottom ${ }^{\mathrm{d}}$ correlation that exhibited the behavior needed at the pot side

The mass flow rate of gases is calculated initially assuming stoichiometric combustion to begin the iterative loop, which continually updates the temperature, velocity, and mass flow profiles, until mass flow converges to a specified tolerance, $1 \mathrm{E}-8 \mathrm{~kg} / \mathrm{s}$. A weighted average of the old and new mass flows is used to prevent overshooting in the next iteration, with a factor of 0.6 
applied to the old value. Any increase in mass flow rate from the initial guess indicates inclusion of excess air due to the buoyant flow. The solution converges when the difference between mass flow rates between iterations is less than the convergence criteria, $1 \mathrm{E}-8$, requiring 10-20 iterations for most stove designs to converge. Additionally, if the pressure losses through the system are greater than the driving pressure due to buoyancy after at least 10 iterations have been completed, a no-flow error message is reported.

\section{Heat Balances}

When the solution has converged, thermal efficiency is calculated per the sum of convective and radiative heat transfer into all regions of the pot (Eq. 42) divided by the firepower.

$$
\eta=\frac{q_{\text {pot }}}{q_{\text {wood }}}
$$

Losses include the sum of the heat flow through the combustion chamber wall, stove top, corner, and shield. Sensible heat lost in the exiting gases is calculated in terms of the exit temperature at height of the pot water.

\section{Model Validation and Verification}

The model was mathematically verified by energy balance (accurate within $0.001 \%$ ), investigating the effects on efficiency of changes in values for element length $\Delta \mathrm{x}$ (1mm showing the optimal grid size), convergence criteria on the mass flow rate of gases $\left(10^{-8} \mathrm{~kg} / \mathrm{s}\right)$, and temperature tolerance $(0.001 \mathrm{~K})$ in the bisection method. 
Based on a literature review of stove studies over the past 30 years, several sets of experimental laboratory results were chosen to develop the needed constants and validate the model (Bussmann and Prasad, 1986; Jetter et al., 2012; MacCarty, Still, and Ogle, 2010). These are catalogued and analyzed by MacCarty and Bryden (2015b). The studies were chosen based on providing results for the specific type of cylindrical shielded fire stove with flat bottom pot modeled and the publishing or making otherwise available the required level of detail available on stove geometry, fuel properties, and operation. All studies used a water boiling test to measure heat transfer efficiency. This provided a consistent data set of 63 data points which include variation of all of the model design variables summarized in chapter 4. Values predicted by the model were compared to experimental results via the L2 norm error (Eq. 43).

$$
\varepsilon_{L 2}=\sqrt{\frac{\sum_{i=1}^{N}\left(\eta_{i, \text { pred }}-\eta_{i, \text { exp }}\right)^{2}}{N}}
$$

It should be noted that there is some uncertainty whether the model or the experimental results are the source of any discrepancies. In recent years, several international conferences, working groups, and independent studies have focused on the potential errors (Taylor, 2009), insufficient repeatability between tests (L'Orange, DeFoort, and Willson, 2012) laboratories, and operators, and lack of representativeness of in-field use (Johnson et al, 2010) of the current dominant WBT protocol (Bailis et al., 2007). A 2009 analysis of the method error and uncertainty including such factors as fuel ash content, unburned char sorting, and char energy content concluded that "If results of the current UCB [University of California-Berkeley] WBT are being used to compare two stove designs, the relative error in thermal efficiency, specific fuel use, firepower, turn-down ratio, and any emissions factors expressed on a per-energy or per- 
mass-of-fuel-consumed basis should be assumed to be ten percent, regardless of that cited as the intra-test error" (Taylor, 2009). As such, the experimental values should be considered with an inherent potential error of at least $\pm 5 \%$.

Additionally, the model is steady-state, while the experimental procedures are not. The WBT begins with the water and stove starting at ambient temperature, whereas the model assumes the pot is already at boiling temperature and the heating effects of the stove body are neglected. Thus, heat transfer to the stove body and pot will both be greater than at steady state during the water and body heating phase while mass flow will likely be reduced due to lower temperature during heating.

\section{Results}

Operation of the model allowed for determination of the constraint space of the model, investigation of radiation transfer and friction factor, and selection of appropriate correlations for free variables and coefficients that most accurately reflect the empirical data. The various combinations are summarized in Table 5 and Figure 4, with discussion following. 
Table 5. Comparison of schema

\begin{tabular}{lcccc} 
& \multicolumn{5}{c}{ Schema } \\
\hline Equation and Parameter Set & $\mathrm{A}$ & $\mathrm{B}$ & $\mathrm{C}$ & $\mathrm{D}$ \\
\hline Bottom Correlation Equation & $(14)$ & $(14)$ & $(44)$ & $(44)$ \\
Shield Correlation Equation & $(28)$ & $(28)$ & $(28)$ & $(45)$ \\
$\phi_{\mathrm{g}}, \phi_{\text {flame }}$ & 1 & 0.2 & 0.2 & 0.2 \\
K Correlation Equation & $(37)$ & $(37)$ & $(37)$ & $(40)$ \\
\hline Results & & & & \\
\hline Pressure Loss > Buoyancy & 19 & 2 & 2 & 2 \\
Outside +- 5\% & 24 & 23 & 15 & 2 \\
L2 Norm Error & $9.0 \%$ & $6.5 \%$ & $5.6 \%$ & $3.0 \%$ \\
Percent of all points within 5\% & $32 \%$ & $60 \%$ & $73 \%$ & $94 \%$ \\
\hline
\end{tabular}



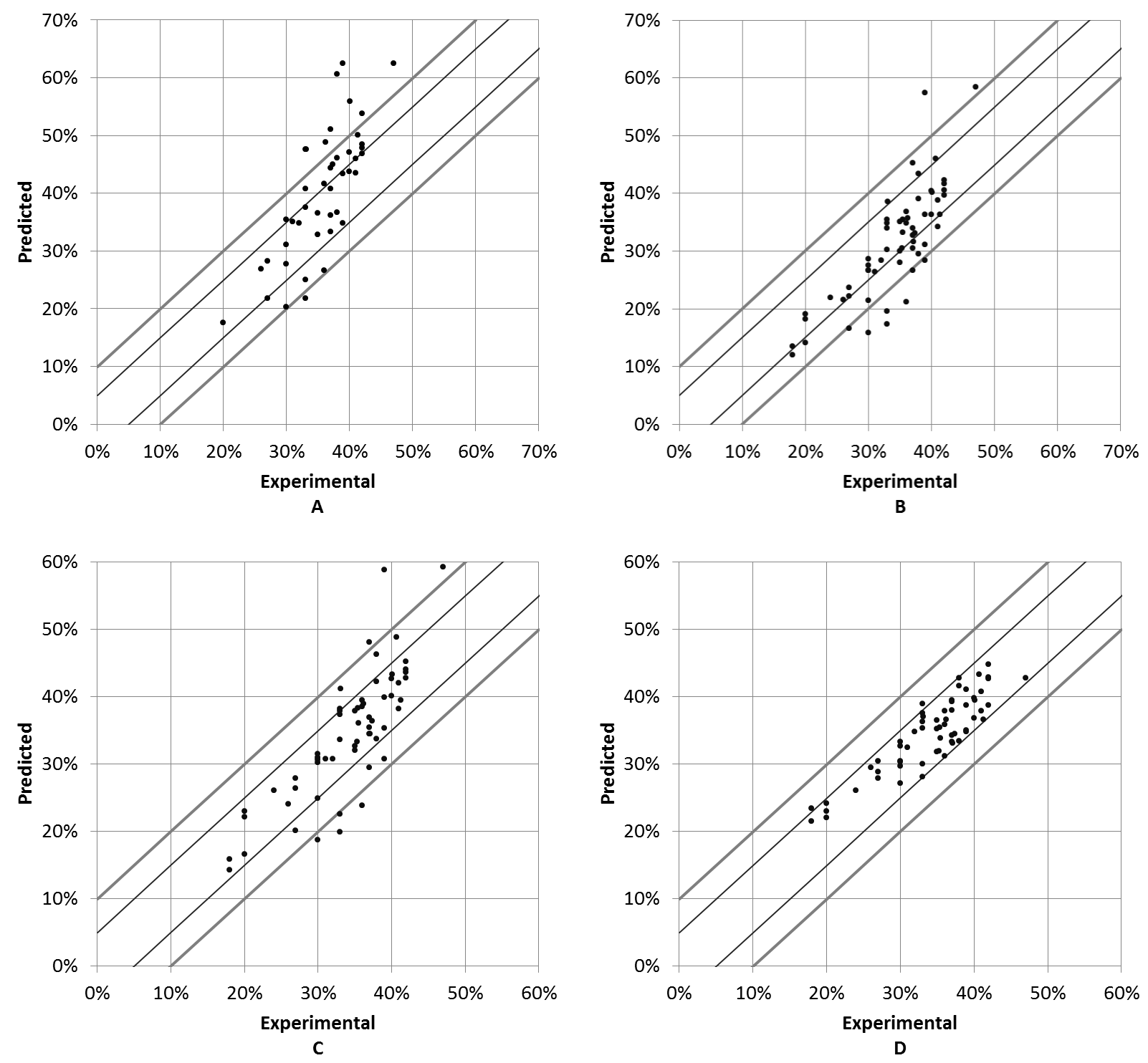

Figure 4. Experimental vs. predicted efficiency, with bounds of $\pm 5 \%, \pm 10 \%$, per schema in Table 5: (A) Correlations from the literature, (B) Correlations from the literature with radiation tuning factor of 0.2, (C) Correlations from the literature with tuning factor of 0.2 and Nusselt correlation for the pot bottom optimized, (D) Tuning factor of 0.2 and optimized Nusselt correlations for the pot bottom and shield, and pot bottom pressure loss 


\section{Geometrical Constraints}

The method of fluid flow calculation is not appropriate for all stove geometries.

Cookstoves where the diameter of the combustion chamber is greater than that of the pot, such as the Ghana Wood from (MacCarty, Still, and Ogle, 2010), are not appropriate for the pipe model of pressure loss due to the large cross sectional area of the "pipe" in which the pot was essentially a "plug" at the pipe exit. Nor are those stoves with short combustion chambers (less than $10 \mathrm{~cm}$ ) and no pot shield through which to develop a buoyant driving force along the flow path. Additionally, extremes in geometry such as small $(5 \mathrm{~mm})$ gaps around the pot can create results in which the pressure losses through the system are greater than the draft generated by buoyancy, such that the model could not run.

Radiation adjustment factor, $\phi$

Many of the early models in the literature either neglected radiative heat transfer or assumed a constant fractional value of the firepower was transferred to the pot. The present model assumes blackbody radiation heat transfer with nonparticipating media, whereas in reality the view between surfaces will be partially blocked by the flame and gases including $\mathrm{CO}_{2}, \mathrm{H}_{2} \mathrm{O}$ and soot. An adjustment factor, $\phi$, was added to the radiation transfers from the fuelbed, $\phi_{\mathrm{fl}}$, and gases, $\phi_{\mathrm{g}}$. When this factor was 1 , the radiative transfer was clearly too high, shown in Figure 4A. As shown in Table 5, the most promising pot-bottom correlations from the literature (Bussmann open fire at the pot bottom) (Eq. 11) paired with Baldwin's constant $\mathrm{Nu}$ at the pot side (Eq. 27), full radiation ( $\phi=1.0)$ resulted in an L2 error of $9.0 \%$, whereas a $\phi=0.2$ shown in Figure 4B resulted in a L2 reduction to $6.5 \%$. More importantly, the number of configurations where the system pressure losses were greater than the buoyancy were also reduced from 19 to 2 . 


\section{Laminar or Turbulent Friction Factor}

The friction factor in channels throughout the stove body was also in question due to Reynolds numbers in the transition region. For laminar flow, the Darcy friction factor is equal to 64/Re, whereas for turbulent flow it can be determined from the Moody diagram, between 0.02 and 0.09 , depending on surface roughness. Testing these options in the model showed minor effects on efficiency, with the laminar correlation creating additional no-flow schemes. An optimization of the turbulent factor from 0-0.2 showed the best value to be between 0.086 and 0.1 between several runs, thus the turbulent factor equal to 0.09 was chosen as the default.

\section{Determination and Optimization of Heat Transfer Correlations}

There are five areas where multiple heat transfer coefficient correlations must be determined. The correlation for turbulent flow over an isothermal plate was deemed appropriate for both an unshielded pot and the region past an existing shield; whereas, the heat transfer correlation along the entire pot bottom and pot side within the shield were in question. Most correlations from the literature were based on experimental data and did not show suitable agreement with this more comprehensive data set, so it was a natural choice to calculate correlations in these regions based on this larger data set. A standard particle swarm optimization (PSO) was used to determine coefficients in Nusselt correlations of formats used in the literature. The PSO was run to simultaneously minimize the L2 error of predicted efficiency, the quantity of data points greater than $\pm 5 \%$ from the experimental data, and the number of points where the system pressure losses were greater than the draft due to buoyancy.

Several options for the format of the Nu correlation under the pot were investigated. These included the formats of Shah (Eq. 12) and Bussmann (Eq. 11), differentiating correlations 
for the pot bottom center and pot bottom above the stovetop (Eq. 13 and 16), and various possible characteristic lengths. A single correlation of the form of Eq. (43) provided the best results.

$$
\overline{\mathrm{Nu}}_{p, \text { bottom }}=0.45 \operatorname{Re}_{D_{c}}^{0.736}\left(\frac{D_{p}}{D_{c}}\right)^{-0.391}
$$

After the pot bottom optimization was complete, a second PSO was run for the correlation within the shielded regions of the pot (Eq. 44).

$$
\overline{\mathrm{Nu}}_{p, \text { side }}=0.001 \operatorname{Re}_{D_{c}}^{1.414}\left(\frac{2 W_{s h}}{D_{p}}\right)^{0.122}
$$

\section{Loss Coefficient for Contractions}

Investigation of the loss coefficients, $\mathrm{K}$, for contractions in flow (Figure 4) revealed the factor used had a significant impact on whether the pressure losses in the system would be greater than that of the buoyancy, especially for small shield gaps. For the pot bottom, the relationship from (Shah and Date, 2011) (Eq. 36) or curve fit from (Shaughnessy, Katz, and Schaffer, 2005) (Eq. 38) both gave the same results since there were no drastic contractions under the pot bottom in the stoves tested. However, for the significant contractions at the pot side (on the order of $50 \%$ or greater), the $\mathrm{K}$ value was critical. It was found that the relationship in (Shah and Date, 2011) gave values that were too low thus overpredicting efficiency and the parabolic curve fit from (Shaughnessy, Katz, and Schaffer, 2005) (Eq. 37) gave too high values at these severe contractions, resulting in a no-flow situation. Upon visual investigation, it was noted that the shape of the curve needed to be a root curve, equal to 0 when the area ratio was 1 , increasing more rapidly initially from 1-2, then leveling off as the area ratio continued to 
increase. Experimentation with values in the code showed the optimal relationship to be that of Eq. (39).
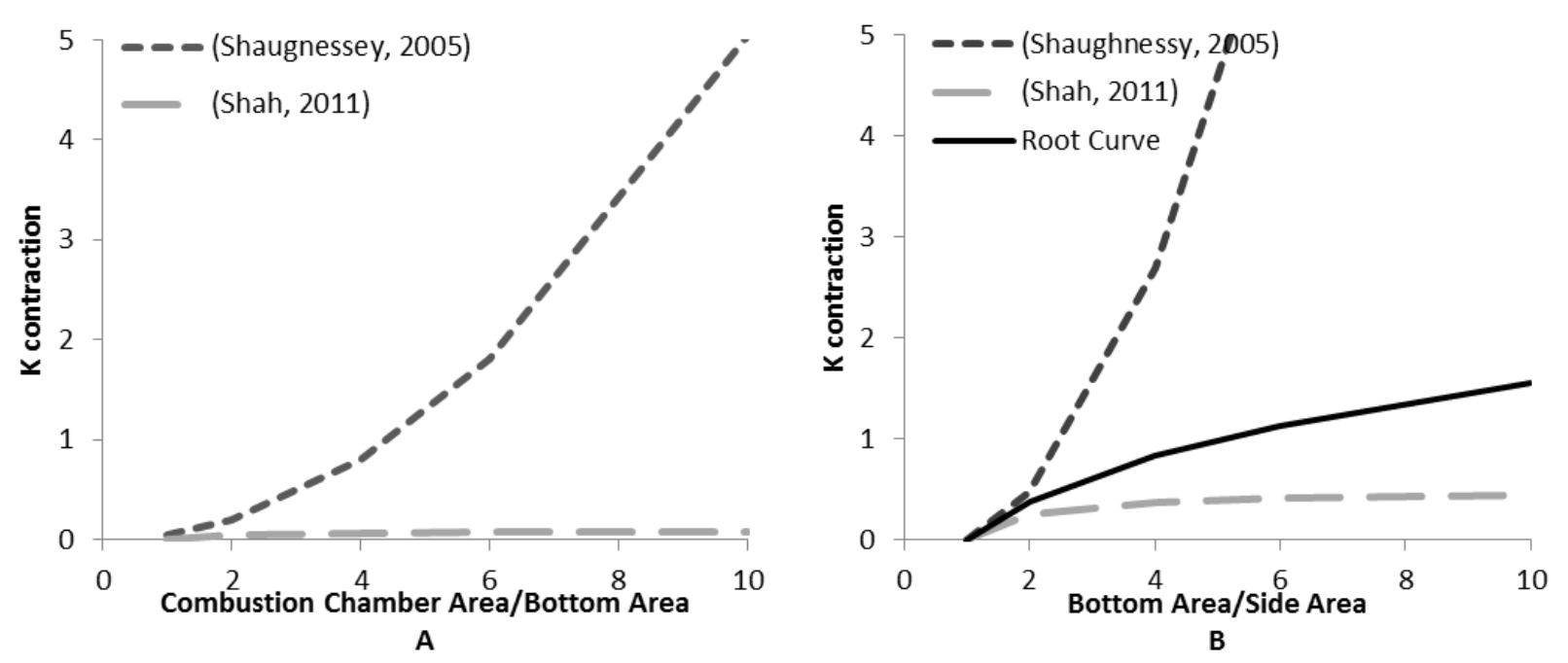

Figure 5. K correlations (A) Pot bottom contraction, (B) Pot side contraction

\section{Comparison to Experimental Data}

Results comparing the various schemes for the total 63 data points are shown in Table 5 and Figure 4. The best correlations from the literature, including the Bussmann correlation for the pot bottom (Eq. 11), constant $\mathrm{Nu}$ of 4.816 (Eq. 27) within the pot shield (Baldwin, 1987), and full radiation is shown in Fig. 4A, with 19 points missing due to pressure losses greater than buoyancy. Figure 4B shows that when reducing the radiation adjustment factor to 0.2 slightly underpredicts efficiency, but most importantly reduces the no-flow error points from 19 to 2 due to greater heat remaining for the buoyant flow. The optimized correlation for the pot bottom reduced the number of outliers (outside $+-5 \%$ ) from 23 to 15 (Figure 4C). Optimizing the correlation for the shielded areas of the pot and applying the improved $\mathrm{K}$ factor for the contraction at the side brought all but two data points to within 5\%, and only two had system 
losses greater than buoyancy, for a total of $94 \%$ of data points predicted accurately (Figure 4D) with an L2 norm error of 3.0\%.

\section{Simulation}

Once validated as above, the model can be used to examine the effects of various design variables and to understand heat flows within the stove. Table 6 provides parameters used for simulations based on two example stove designs that were tested empirically, including (a) Stove A, the one-door rocket stove with skirt at high power tested by both Jetter et al. (2012) and MacCarty et al. (2010); and (b) Stove B, a particular variation of the metal shielded fire stove tested by (Bussmann and Prasad, 1986). An example of heat flow analysis for these stoves is provided in Table 7. Proportions agree relative to several scantly-detailed heat balances of stoves presented in (Prasad, Sangen and Visser, 1985). The heat flow analysis shows that the two stoves have similar firepower and thermal efficiency, yet the mechanisms for heat transfer into the pot are considerably different. Only $8 \%$ of the heat transfer into the pot in Stove A is provided by radiation, while Stove B has more than twice that due to the considerably wider and shorter combustion chamber. Whereas the narrow combustion chamber and small gap under the pot in Stove A create a significant increase in convective heat transfer through the pot bottom relative to Stove B. In addition, despite significant differences in stove body construction, with Stove A constructed of an insulative ceramic combustion chamber and Stove B of sheet metal, the stove body losses are similar. The majority of losses are represented by heat remaining in the exhaust gases, suggesting that design changes should likely focus on increasing heat transfer to the pot rather than decreasing losses from the body. 
Table 6. Parameters of example simulated cookstove designs

\begin{tabular}{lcccc}
\hline & & & Stove & Stove \\
& & & $\mathrm{A}$ & $\mathrm{B}$ \\
\hline Stove Variables & & & & \\
Combustion chamber diameter & $\mathrm{D}_{\mathrm{c}}$ & $(\mathrm{cm})$ & 10.0 & 18.0 \\
Combustion chamber height & $\mathrm{H}_{\mathrm{c}}$ & $(\mathrm{cm})$ & 23.3 & 10.0 \\
Gap at combustion chamber & $\mathrm{W}_{\mathrm{c}}$ & $(\mathrm{cm})$ & 2.5 & 3.5 \\
Gap at pot corner & $\mathrm{W}_{\mathrm{p}}$ & $(\mathrm{cm})$ & 1.0 & 3.5 \\
Shield gap & $\mathrm{W}_{\mathrm{sh}}$ & $(\mathrm{cm})$ & 0.8 & 1.0 \\
Stove diameter & $\mathrm{D}_{\text {stove }}$ & $(\mathrm{cm})$ & 26 & 18.1 \\
Shield height & $\mathrm{H}_{\mathrm{sh}}$ & $(\mathrm{cm})$ & 8.0 & 17.8 \\
Shield thickness & $\mathrm{t}_{\mathrm{sh}}$ & $(\mathrm{cm})$ & 0.05 & 0.05 \\
Stove body conductivity & $\mathrm{k}_{\mathrm{stove}}$ & $(\mathrm{W} / \mathrm{m} \cdot \mathrm{K})$ & 1.0 & 26.2 \\
Pot Variables & & & & \\
Pot diameter & $\mathrm{D}_{\mathrm{p}}$ & $(\mathrm{cm})$ & 24.0 & 24.0 \\
Pot height & $\mathrm{H}_{\mathrm{p}}$ & $(\mathrm{cm})$ & 11.1 & 11.1 \\
Pot volume & $\mathrm{V}_{\mathrm{p}}$ & $(\mathrm{L})$ & 5.0 & 5.0 \\
Fuel Variables & & & & \\
Fuel Heating Value & $\mathrm{LHV}_{\mathrm{f}}$ & $(\mathrm{MJ} / \mathrm{kg})$ & 19.26 & 18.60 \\
Fuel Moisture Content & $\mathrm{MC}_{\mathrm{f}, \mathrm{as}-\mathrm{rec}} \mathrm{d}$ & & $14 \%$ & $0 \%$ \\
Firepower & $\mathrm{q}$ & $(\mathrm{kW})$ & 4.0 & 4.0 \\
\hline
\end{tabular}


Table 7. Energy balance

\begin{tabular}{|c|c|c|c|c|}
\hline & \multicolumn{2}{|c|}{ Stove A } & \multicolumn{2}{|c|}{ Stove B } \\
\hline & Watts & Fraction $^{\mathrm{a}}$ & Watts & Fraction $^{\mathrm{a}}$ \\
\hline Moisture evaporation & 88 & & 0 & \\
\hline Equivalent daf Firepower & 4024 & & 4000 & \\
\hline As-received Firepower & 4112 & & 4000 & \\
\hline Convection: & & & & \\
\hline Pot center & 215 & $16 \%$ & 297 & $22 \%$ \\
\hline Pot bottom & 699 & $54 \%$ & 191 & $14 \%$ \\
\hline Pot sides & 391 & $30 \%$ & 557 & $42 \%$ \\
\hline Total Convection to Pot & 1305 & $92 \%$ & 1045 & $79 \%$ \\
\hline \multicolumn{5}{|l|}{ Radiation: } \\
\hline Fire to pot & 18 & $15 \%$ & 212 & $74 \%$ \\
\hline Wall to pot & 13 & $11 \%$ & 18 & $6 \%$ \\
\hline Stovetop to pot & 56 & $49 \%$ & 16 & $5 \%$ \\
\hline Shield to pot & 28 & $24 \%$ & 40 & $14 \%$ \\
\hline Total Radiation to Pot & 115 & $8 \%$ & 286 & $21 \%$ \\
\hline Total to Pot & 1420 & $35 \%$ & 1331 & $33 \%$ \\
\hline \multicolumn{5}{|l|}{ Losses: } \\
\hline Wall & 239 & $6 \%$ & 124 & $3 \%$ \\
\hline Stovetop & 333 & $8 \%$ & 122 & $3 \%$ \\
\hline Corner & 85 & $2 \%$ & 200 & $5 \%$ \\
\hline Shield & 249 & $6 \%$ & 302 & $8 \%$ \\
\hline Sensible in Exhaust & 1698 & $42 \%$ & 1921 & $48 \%$ \\
\hline Total Loss & 2604 & $65 \%$ & 2669 & $67 \%$ \\
\hline
\end{tabular}

a Italic $=$ to pot, Bold=total

Mass flow, temperature, and resulting heat transfer coefficient and velocity data of those two stoves are shown in Table 8, which includes a comparison to rough temperature measurements taken during steady-state operation of the one-door rocket stove. Temperature comparisons show good agreement for all temperatures with the exception of the fuel bed and flame temperatures which were overpredicted and underpredicted, respectively. The mass flow 
through Stove B is about 33\% higher than Stove A, creating increased excess air and reduced temperatures. Velocities and heat transfer coefficients in Stove B are also proportionally lower as a result.

Table 8. Flow and temperature data

\begin{tabular}{lcc|c}
\hline & Stove A & Measured & Stove B \\
\hline Iterations & 14 & 8 \\
Mass flow $(\mathrm{kg} / \mathrm{s})$ & 0.0049 & & 0.0066 \\
$\lambda$ & 3.7 & 4.9 \\
Temperatures $\left({ }^{8} \mathbf{C}\right)$ & & & \\
Fuel bed & 1274 & $790-860$ & 1039 \\
Flame & 674 & $730-830$ & 477 \\
Pot center & 470 & $430-590$ & 451 \\
Pot corner & 460 & $320-360$ & 428 \\
Exit & 337 & $230-330$ & 303 \\
Heat Transfer Coefficients $\left(\mathbf{W} / \mathbf{m}^{\mathbf{2} \cdot \mathbf{K})}\right.$ & & \\
Pot center & 45 & & 26 \\
Pot bottom & 44 & 28 \\
Average pot side & 14 & 25 \\
Velocities $(\mathbf{m} / \mathbf{s})$ & & & 0.6 \\
Chamber & 1.7 & 1.5 \\
Pot side & 1.5 & & \\
\hline
\end{tabular}

A simulation of variable thermal conductivity for Stove A is shown in Table 9, with all variables held constant at levels in Table 6 except the stove body conductivity. The exception to this is the metal case which represents a single-walled $0.5 \mathrm{~mm}$ metal body with no insulation. Values for stove body conductivity are varied to represent typical cookstove combustion chamber materials. It is shown that with all other variables held constant, efficiency can be impacted by as much as $10 \%$ when moving from the most insulative (perlite) to least insulative 
(concrete) combustion chamber materials. Further analysis can explore the trade-offs between wall material and thickness.

Table 9. Insulation Study

\begin{tabular}{lcc}
\hline Material & $\begin{array}{c}\text { Conductivity } \\
(\mathrm{W} / \mathrm{m} \cdot \mathrm{K})\end{array}$ & $\begin{array}{c}\text { Predicted } \\
\text { Efficiency }\end{array}$ \\
\hline Perlite & 0.05 & $43.2 \%$ \\
Pumice & 0.6 & $36.4 \%$ \\
Fireclay brick & 1 & $35.2 \%$ \\
Concrete & 1.7 & $34.3 \%$ \\
Metal & 26.2 & $35.5 \%$ \\
\hline
\end{tabular}

The effects of varying operating conditions such as fuel moisture content, firepower, and pot diameter on Stove A are shown in Table 10, demonstrating how the model can help to predict the effects of in-field conditions on stove performance. The experimental moisture content variation of (Jetter et al., 2012) showed essentially no reduction in efficiency between dry $(\sim 10 \%)$ and wet $(\sim 20 \%)$ wood for the two rocket stoves, as did the model.

Table 10. Effect of moisture content, firepower, and pot diameter

\begin{tabular}{cc|cc|cc}
\hline $\begin{array}{c}\mathrm{MC}_{\text {wood }} \\
(\% \text { asrecd }\end{array}$ & Efficiency & $\begin{array}{c}\text { Firepower } \\
(\mathrm{W})\end{array}$ & Efficiency & $\begin{array}{c}\mathrm{D}_{\mathrm{p}} \\
(\mathrm{m})\end{array}$ & Efficiency \\
\hline $0 \%$ & $36.6 \%$ & 2000 & $31.0 \%$ & & \\
$5 \%$ & $36.2 \%$ & 3000 & $34.2 \%$ & 0.16 & $36.0 \%$ \\
$10 \%$ & $35.9 \%$ & 4000 & $35.9 \%$ & 0.2 & $35.8 \%$ \\
$15 \%$ & $35.4 \%$ & 5000 & $36.8 \%$ & 0.24 & $35.9 \%$ \\
$20 \%$ & $35.0 \%$ & 6000 & $37.3 \%$ & & \\
$25 \%$ & $34.5 \%$ & & & & \\
$30 \%$ & $33.9 \%$ & & & & \\
\hline
\end{tabular}


A sensitivity analysis of the five major geometrical variables for Stove A is provided in Figure 6, indicating that the pot shield gap has the most significant impact on efficiency while the combustion chamber diameter is the least sensitive of the five variables. These trends are also in agreement with the observations from the data set detailed in (MacCarty and Bryden, 2015b).

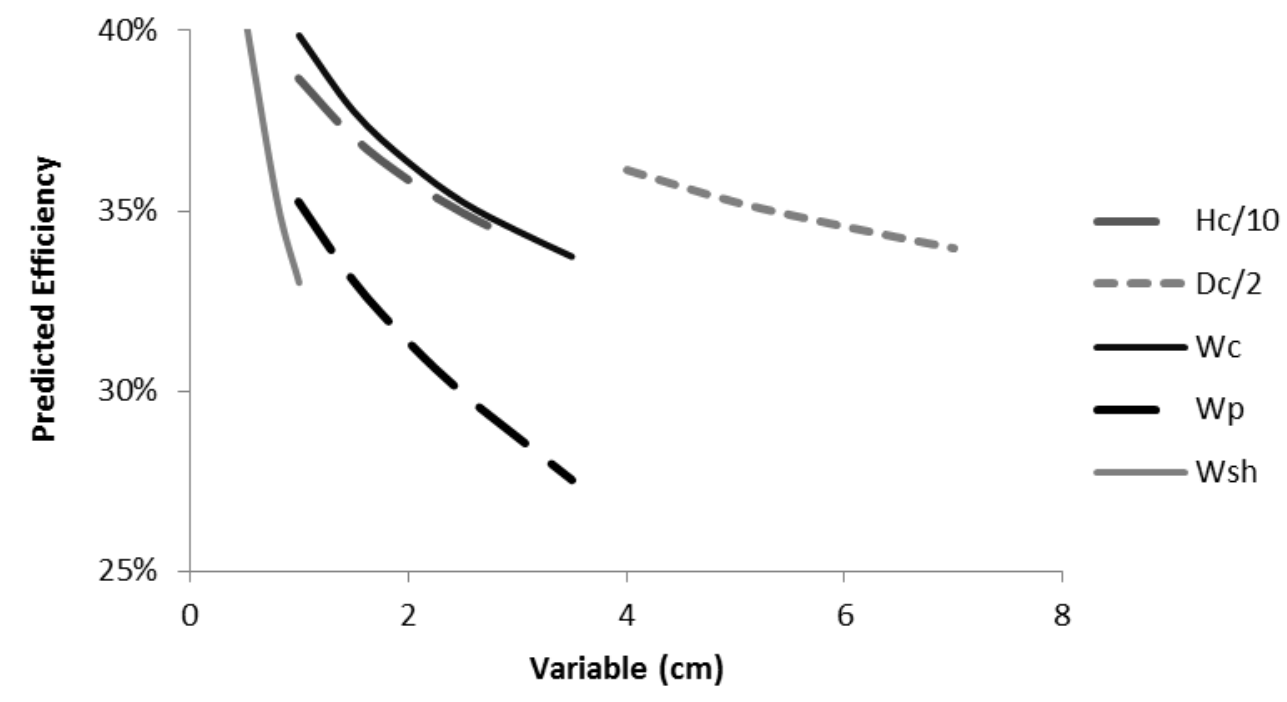

Figure 6. Sensitivity analysis of five geometrical design variables

\section{Conclusions and Future Work}

The equation set presented in this paper showed good success at predicting the efficiency of a wide array of stove designs. Pairing standard equations for fluid flow in a pipe successfully indicated the flow behavior for this type of cylindrical shielded-fire stove. Several standard heat transfer correlations paired with empirical Nusselt-format optimizations derived from a large data set for the flat-bottom and shielded pot regions successfully predict $94 \%$ of measured heat transfer efficiencies within 5\%. The 63 experimental data points used were the only results 
available with sufficient detail for validating the model, indicating a need for an accepted standard of experiments and reporting methods that are useful for modeling of such stoves. Experiments and CFD can be used to verify convective heat transfer coefficients reported by the model, as well as to verify the heat fluxes through various regions.

Although the model is able to predict heat transfer, it does not indicate the resulting combustion efficiency or practicality of the design, thus engineering judgment and experiment should be used to test the utility of any designs based on such a model. Additional research is needed to include issues of emissions including black carbon and to include models for a broader variety of cookstoves. In many cases, reduction of emissions from a cookstove is as much or more important of a goal in cookstove programs; therefore, to be fully useful the model should be updated to include solid and gas phase combustion and pollutant formation processes paired with relevant experimental data for validation.

Although many of these findings confirm what has been previously known through thumb rules, the model is able to quantify the various stove configurations without the need for extensive experiments. This will enable a broader and more thorough search of the available designs during the conceptual and preliminary design stages. Testing the model's aid in design of a new cookstove given specific constraints for community, material, and cost needs would be a good step toward investigating the power of modeling in design. Any number of design variables can be optimized in conjunction with design variables set based on user needs.

\section{Acknowledgements}


The authors gratefully acknowledge the financial support of Nordica MacCarty by the United

States National Science Foundation Graduate Research Fellowship Program (Grant no.

DGE0751279).

\section{References}

Bailis R, Ogle D, MacCarty N, Still D, Smith KR, Edwards R. 2007. The Water Boiling Test, Version 3.0. Technical report, University of California, Berkeley. pciaonline.org/node/1048 [accessed 4 November 2014].

Baldwin, S. 1987. Biomass stoves: Engineering design, development, and dissemination. $\mathrm{PhD}$ Dissertation. Princeton University, Princeton, New Jersey.

Bhattacharya SC, Albina DO, Khaing AM. 2002. Effects of selected parameters on performance and emission of biomass-fired cookstoves. Biomass and Bioenergy 23:387-395.

Biswas WK, Lucas NJD. 1997. Energy consumption in the domestic sector in a Bangladesh village. Energy 22(8):771-6.

Bond TC, Sun H. 2005. Can Reducing Black Carbon Emissions Counteract Global Warming? Environmental Science and Technology 39:5921-6.

Bruce N, Rehfuess E, Mehta S, Hutton G, Smith KR. 2006. Indoor air pollution, Disease Control Priorities in Developing Countries 2nd ed. Oxford University Press, New York. Ch42:793-816.

Bryden KM, Ashlock DA, McCorkle DS, Urban GL. 2003. Optimization of heat transfer utilizing graph based evolutionary algorithms. International Journal of Heat and Fluid Flow 24:267-277.

Bussmann P. 1988. Woodstoves: Theory and Applications in Developing Countries. PhD dissertation. Eindhoven University of Technology, Eindhoven, the Netherlands.

Bussmann PJT, Prasad KK. 1982. Model predictions of temperature and velocity profiles in turbulent diffusion buoyant flames. Proceedings of the 7th International Heat Transfer Conference.

Bussmann PJT, Prasad KK. 1986. Parameter Analysis of a Simple Wood-Burning Cookstove. Proceedings of the 8th International Heat Transfer Conference.

Bussmann PJT, Visser P, Prasad KK. 1983. Open Fires: Experiments and Theory. Proceedings of the Indian Academy of Sciences, Engineering Sciences 6(1):1-34.

Bussmann, PJT, Prasad, KK. 1986. Parameter Analysis of a Simple Wood-Burning Cookstove. Proceedings of the 8th International Heat Transfer Conference 6:3085-3090 
Daioglou V, van Ruijven BJ, van Vuuren DP. 2012. Model projections for household energy use in developing countries. Energy 38(1)601-15.

Date A. 2011. Analytic Combustion: With Thermodynamics, Chemical Kinetics, and Mass Transfer. Cambridge University Press.

Date A. 1988. Investigation of CTARA wood-burning stove. Part II. Analytical Investigation. Sadhana 13(4):295-317.

De Lepeleire G, Christiaens M. 1983. Heat transfer and cooking woodstove modelling. Proceedings of the Indian Academy of Sciences, Engineering Sciences 6(1):35-46.

De Lepeleire, G, Prasad, KK, Verhaart P, and Visser P. 1981. A woodstove compendium. Eindhoven University of Technology. Eindhoven, the Netherlands.

Energy for Sustainable Development (ESD) Ltd. 2000. Poverty reduction aspects of successful improved household stoves programmes. United Kingdom Department for International Development (DFID), Knowledge and Research Project, No. R7368 http://www.dfid.gov.uk/r4d/PDF/Outputs/R7368.pdf [accessed 11.13.12].

Engineering Equation Solver (EES). 2011. S.A. Klein.

Hannai SK, Hessari E, Fardadi M, Jeddi MK. 2006. Mathematical modeling of cooking pots' thermal efficiency using a combined experimental and neural network method. Energy 31:2969-85.

Hansen J, Sato M, Kharecha P, Russell G, Lea DW and Siddall M. 2007. Climate change and trace gases. Phil. Trans. R. Soc. Lond. A(365):1925-54.

Incropera FP. DeWitt DP, Bergman TL, Lavine AS. 2007. Fundamentals of Heat and Mass Transfer, $6^{\text {th }}$ Edition. John Wiley \& Sons.

International Energy Agency (IEA). 2010. Energy poverty: how to make modern energy access universal? World Energy Outlook, Paris.

Jetter J, Zhao Y, Smith KR, Khan B, Yelverton T, DeCarlo P, et al. 2012. Pollutant emissions and energy efficiency under controlled conditions for household biomass cookstoves and implications for metrics useful in setting international test standards. Environmental Science and Technology. 46(19):10827-10834.

Johnson M, Edwards R, Berrueta V, Masera, O. 2010. New approaches to performance testing of improved cookstoves. Environmental Science and Technology 44:368-74.

Johnson NG, Bryden KM. 2012a. Energy supply and use in a rural West African village. Energy 43: 283-292. 
Johnson NG, Bryden KM. 2012b. Factors affecting woodfuel consumption in household cookstoves in an isolated rural West African village. Energy 46:310-321.

Legros G, Havet I, Bruce N, Bonjour S. 2009. The Energy Access Situation in Developing Countries. World Health Organization and UNDP. In: Rijal K, Takada M, Dora C, et al. New York: United Nations Development Programme.

http://content.undp.org/go/cms-service/stream/asset/?asset_id=2205620 [accessed 11.13.12].

Lim S, Vos T, Flaxman AD, Danaei G, Shibuya K, Adair-Rohani H. et al. 2012. A comparative risk assessment of burden of disease and injury attributable to 67 risk factors and risk factor clusters in 21 regions, 1990-2010: a systematic analysis for the Global Burden of Disease Study 2010. Lancet 380:2224-60.

L'Orange C, DeFoort M, Willson B. 2012. Influence of testing parameters on biomass stove performance and development of an improved testing protocol. Energy for Sustainable Development 16:3-12.

MacCarty NA, Bryden KM. 2015a. Modeling of Household Biomass Cookstoves: A Review. Energy for Sustainable Development 26:1-13.

MacCarty NA, Bryden KM. 2015b. A unified set of experimental data for cylindrical, natural draft, shielded single pot wood-fired cookstoves. Energy for Sustainable Development, 26:62-71.

MacCarty NA, Still DK, Ogle DM. 2010. Fuel use and emissions performance of fifty cooking stoves in the laboratory and related benchmarks of performance. Energy for Sustainable Development. 14:161-171.

McCorkle DS, Bryden KM, Carmichael CG. 2003. A new methodology for evolutionary optimization of energy systems. Comput. Methods Appl. Mech. Engrg. 192:5021-5036.

Nag PK. 2006. Heat and Mass Transfer, $2^{\text {nd }}$ Edition. Tata McGraw-Hill Education.

Prasad KK, Sangen E, Visser P. 1985. Woodburning Cookstoves. Advances in Heat Transfer. Elsevier 17:159-317.

Prasad KK, Sangen E. 1983. Technical Aspects of Woodburning Cookstoves. Eindhoven University of Technology. Eindhoven, the Netherlands.

Prasad KK. 1981. Some studies on open fires, shielded fires, and heavy stoves. Eindhoven University of Technology, Eindhoven, the Netherlands.

Pugh S. 1990. Total Design: Integrated Methods for Successful Product Engineering, Prentice Hall, Harlow, England.

Ragland KW, Baker AJ. 1991. Properties of Wood for Combustion Analysis. Bioresource Technology 37:161-168. 
Ragland KW, Bryden KM. 2011. Combustion Engineering, Second Edition. CRC Press, Florida.

Rehfuess E. 2006. Fuel for life - household energy and health. World Health Organization, Geneva, Switzerland. http://www.who.int/indoorair/publications/fuelforlife.pdf [accessed 11.13.12].

Ruiz-Mercado I, Masera O, Zamora H, Smith KR. 2011. Adoption and sustained use of improved cookstoves. Energy Policy 39(12):7557-66.

Shah R, Date AW. 2011. Steady-State Thermochemical Model of a Wood-burning cook stove. Combustion Science and Technology 183(4):321-346.

Shaughnessy EJ Jr, Katz IM, Schaffer JP. 2005. Introduction to Fluid Mechanics. Oxford University Press.

Smith KR, Mehta S, Maeusezahl-Feuz M. 2004. Indoor smoke from household solid fuels, in Ezzati M., Rodgers A.D., Lopez A.D., and Murray C.J.L. (eds) Comparative Quantification of Health Risks: Global and Regional Burden of Disease due to Selected Major Risk Factors. World Health Organization, Geneva, Switzerland. Volume 2 of 3:1437-95.

Taylor III, RP. 2009. The uses of laboratory testing of biomass cookstoves and the shortcomings of the dominant U.S. protocol. M.S. Thesis, Iowa State University, Ames, Iowa, USA.

Turns S. 2000. An Introduction to Combustion. McGraw-Hill, USA.

Urban GL, Bryden KM, Ashlock DA. 2002. Engineering optimization of an improved plancha stove. Energy for Sustainable Development 6(2):9-19. 